\title{
Garcin syndrome caused by sphenoid bone metastasis of lung cancer: a case study
}

\author{
Satoshi Fukai ${ }^{1}$, Naoyuki Okabe ${ }^{1}$, Hayato Mine ${ }^{1}$, Hironori Takagi ${ }^{1}$ and Hiroyuki Suzuki ${ }^{*}$
}

\begin{abstract}
Background: Garcin syndrome, which consists of unilateral palsies of almost all cranial nerves without either sensory or motor long-tract disturbances or intracranial hypertension, can be caused by malignant tumors at the skull base. The case of a patient with lung cancer that metastasized to the sphenoid bone and resulted in Garcin syndrome is presented.

Case presentation: A 76-year-old woman was diagnosed as having non-small cell lung cancer with pericardial and diaphragmatic infiltration, CT4N1M0, stage 3A. The left lower lobectomy with concomitant resection of the pericardium and diaphragm was performed. The pathological diagnosis was pleomorphic carcinoma, pT2bNOMO, stage 1B. She was then followed in the surgery clinic, and 2 months after surgery, she visited an emergency room complaining of headache and diplopia. Neurological examination showed the left $\mathrm{V}, \mathrm{V} 1$, and $\mathrm{VI}$ cranial nerve palsies. Metastatic tumor with bone destruction was found in the left sphenoid sinus on head computed tomography $(\mathrm{CT})$ and contrast magnetic resonance imaging (MRI), and she was diagnosed with Garcin syndrome caused by sphenoid bone metastasis of lung cancer. Irradiation was performed as palliative treatment, but her neurological findings did not improve. Her general condition gradually worsened, and she died 5 months after surgery.

Conclusions: Bone metastasis of lung cancer occurs frequently, but sphenoid bone metastasis is extremely rare. In this case report, Garcin syndrome caused by lung cancer is discussed in the context of the few previous reports.
\end{abstract}

Keywords: Garcin syndrome, Lung cancer, Bone metastasis, Sphenoid bone, Basal bone, Cranial nerve palsy

\section{Background}

Guillain-Alajouanine-Garcin syndrome (Garcin syndrome) is a rare syndrome first reported by Garcin in 1926 [1]. Garcin syndrome consists of unilateral palsies of almost all cranial nerves without sensory or motor long-tract disturbances or intracranial hypertension that can be caused by malignant tumors at the skull base. In Garcin's report, it is written as "almost" all cranial nerves, and although the specific number of cranial nerves is not clarified, all of I to XII cranial nerve palsies can occur.

Garcin syndrome could be caused by primary tumors of the skull base, such as nasopharyngeal tumors [1] and epipharyngeal rhabdomyosarcoma [2]; metastatic

\footnotetext{
* Correspondence: hiro@fmu.ac.jp; deep3104@gmail.com

${ }^{2}$ Department of Chest Surgery, Fukushima Medical University, 1 Hikarigaoka

Fukushima, Fukushima 960-1295, Japan

Full list of author information is available at the end of the article
}

tumors, such as breast cancer [3], prostate cancer [4], and lung cancer [5-10]; and inflammatory diseases, such as mucormycosis [11]. A case of sphenoid bone metastasis of lung cancer with Garcin syndrome is described.

\section{Case presentation}

A 76-year-old woman lost $3 \mathrm{~kg}$ in 3 months and visited a primary care clinic in September 2014. She had never smoked, and her Eastern Cooperative Oncology Group (ECOG) performance status (PS) was 1. Computed tomography (CT) showed a tumor of about $6 \mathrm{~cm}$ in the left lower lobe. Bronchoscopic biopsy did not show malignant cells, but sarcomatoid cancer was suspected with bronchoalveolar lavage fluid (BALF). Preoperative brain magnetic resonance imaging (MRI) showed no brain metastasis, and metastasis was not found in whole-body positron emission tomography (PET) CT. In contrast CT, the tumor was widely in contact with the 


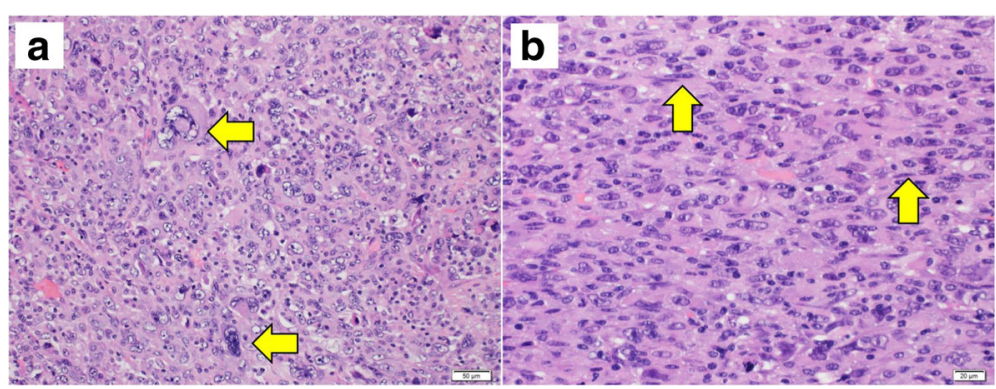

Fig. 1 a Pathological examination shows pleomorphic carcinoma with giant cells (H\&E staining). b Many spindle cells are observed (H\&E staining)

pericardium and the diaphragm. After examination, a non-small cell lung cancer with pericardial and diaphragmatic invasion, cT4N1M0, stage3A, was diagnosed. The left lower lobectomy with concomitant resection of the pericardium and diaphragm and nodal dissection (ND)2a-2 was then performed. The pathological diagnosis was pleomorphic carcinoma (Fig. 1), pT2bN0M0, stage $1 \mathrm{~B}$. The patient was followed in the surgery clinic without chemotherapy or radiotherapy. Two months after surgery, she visited an emergency room with chief complaints of headache that the throbbing of the left temple makes it impossible to open her eyes and diplopia.

On neurological examination, she showed left trochlear (IV) and abducens (VI) nerve palsies and had pain in the left trigeminal nerve first branch area (V1). Head CT showed bone destruction at the left sphenoid sinus (Fig. 2a). Gadolinium-enhanced MRI of the brain showed a contrast-enhanced tumor (Fig. 2b). Based on the neurologic examination and imaging findings, Garcin syndrome caused by sphenoid bone metastasis of lung cancer was diagnosed. Five-gray irradiation was performed four times to control her neurological symptoms, but they did not improve. Subsequently, she was given zoledronic acid in the surgery clinic, but it was ineffective. Three months after surgery, whole-body PET and CT showed cancer spread to involve the right ninth rib and the left adrenal gland. Her general condition gradually worsened, and she died in March 2015, about 5 months after surgery.

\section{Discussion and conclusions}

Garcin syndrome is defined as meeting the following four diagnostic criteria: (1) unilateral palsies of the cranial nerves, (2) neither sensory nor motor longtract disturbance, (3) no intracranial hypertension, and (4) an osteoblastic lesion in the skull base [1]. It has unique clinical symptoms and is a rare syndrome. There are Collet-Sicard syndrome, cavernous sinus syndrome, Tolosa-Hunt syndrome which have similar clinical findings with Garcin syndrome, but these syndromes are paralysis of a certain cranial nerve (e.g., Collet-Sicard is IX to XII) and are defined also by nerve inflammation. Garcin syndrome, as shown, distinguishes it from those syndromes in that it can occur in all cranial nerves and cannot be diagnosed without osteoclastic lesions. The sphenoid sinus is a cavity inside the butterfly bone in the midline of the skull base and is one of the paranasal sinuses. The

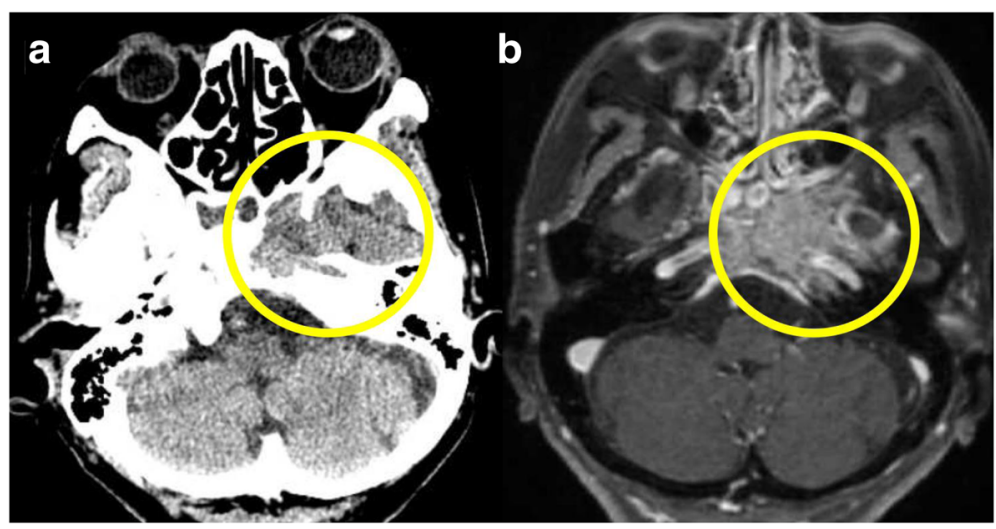

Fig. 2 a Head CT shows bone destruction at the left sphenoid sinus. b Gadolinium-enhanced MRI (T1WI) of the brain shows a contrast-enhanced tumor at the left sphenoid sinus 
Table 1 Characteristics of cases of lung cancer with Garcin syndrome

\begin{tabular}{|c|c|c|c|c|c|}
\hline No. & $\begin{array}{l}\text { Age (years) } \\
\text { /sex }\end{array}$ & Histology & $\begin{array}{l}\text { Cranial nerves } \\
\text { affected }\end{array}$ & Type of metastasis & Author, year \\
\hline 1 & $69 / F$ & Adenocarcinoma & $\begin{array}{l}\text { Rt. II, V, VI } \\
\text { Lt. II, III, IV, V, VI }\end{array}$ & Metastasis to the skull base & Imanishi et al. 1974 [5] \\
\hline 2 & $52 / F$ & Adenocarcinoma & Rt. $X, X I, X \|$ & Metastasis to the skull base & Fujii et al. 2007 [6] \\
\hline 3 & $60 / F$ & Adenocarcinoma & Rt. VII, VIII & Metastasis to the skull base & Toh et al. 2007 [7] \\
\hline 4 & $50 / \mathrm{M}$ & Adenocarcinoma & Lt. V, VII, VIII, IX, X, XII & Cancerous meningitis & Aida et al. 2010 [8] \\
\hline 5 & $65 / F$ & Non-small cell carcinoma & $\begin{array}{l}\text { Rt. III, IV, VII } \\
\text { Lt. IX,X }\end{array}$ & $\begin{array}{l}\text { Cancer invasion to the dura } \\
\text { mater }\end{array}$ & Nagashima et al. 2011 [9] \\
\hline 6 & $61 / F$ & Small cell carcinoma & Lt. IX, XI, XII & $\begin{array}{l}\text { Metastasis to the left posterior } \\
\text { cranial fossa }\end{array}$ & Moriyama et al. 2013 [10] \\
\hline Present case & $76 / F$ & Pleomorphic carcinoma & Rt. IV, V1, VI & Metastasis to the sphenoid bone & \\
\hline
\end{tabular}

sphenoid sinus is located in the medial of the superior orbital fissure which the III, IV, V1, and VI cranial nerves pass, and in this case, the cranial nerves were compressed by the tumor. Many reports of Garcin syndrome assume that it originates from a bone invading malignant tumor, such as a tumor of the nucleus of the skull base and nasopharynx or metastatic tumor from a remote organ to the skull. Lung cancer is the third most likely to develop bone metastasis following breast cancer and prostate cancer [12]. The rate of bone metastasis at necropsy of lung cancer is reported to be about 20-50 [13]. Furthermore, the histopathological diagnosis of this case was pleomorphic carcinoma, which is reported to be more likely to cause distant metastasis than other types of non-small cell lung cancer [14]. Skull metastasis of lung cancer are reported to be 5 cases in 611 cases $(0.4 \%)$ of single bone metastasis of lung cancer [12]. Since skull base bone metastasis is rarer than skull metastasis, the overall incidence of Garcin syndrome caused by lung cancer is estimated to be much less than $0.4 \%$. In the previous reports, there were six cases with Garcin syndrome due to lung cancer, including subtypes that did not satisfy all diagnostic criteria (Table 1) [5-10]. To date, there is no specific therapy for Garcin syndrome. In the present case, radiotherapy and zoledronic acid were given as a treatment for bone metastasis, but there was no neurological improvement. A case of small cell lung cancer with neurological improvement after only carboplatin + etoposide therapy has been reported [10]. There are few cases reporting neurological improvement, but there is a possibility that symptoms can be improved by correctly diagnosing Garcin syndrome.

A case of recurrence of lung cancer resulting in sphenoid bone metastasis and Garcin syndrome was described. If a patient with lung cancer develops strange neurological manifestations, Garcin syndrome with skull base metastasis must be considered, even though it is an uncommon syndrome. If Garcin syndrome is suspected, it is necessary first to perform contrast MRI and to consult with neurology to clarify neurological findings. Although there is no treatment to be done in an emergency, neurosurgery and radiotherapy are considered next depending on the cause of the disease.

\section{Abbreviations}

BALF: Bronchoalveolar lavage fluid; CT: Computed tomography; ECOG PS: Eastern Cooperative Oncology Group performance status; MRI: Magnetic resonance imaging; ND: Nodal dissection; PET: Positron emission tomography

\section{Acknowledgements}

Not applicable.

\section{Funding}

There is no funding for the research.

\section{Availability of data and materials}

Data sharing is not applicable to this article as no datasets were generated or analyzed during the current study.

\section{Authors' contributions}

SF collected and assembled the data and drafted the article. NO constructed the conception and design of the article. HM and HT helped in collecting data and creating articles. HS helped to draft the article and finally approved the article. All authors read and approved the final manuscript.

Ethics approval and consent to participate

Not applicable.

\section{Consent for publication}

Written informed consent was obtained from the patient for the publication of this case report and accompanying images. A copy of the written consent is available for review by the editor-in-chief of this journal.

\section{Competing interests}

The authors declare that they have no competing interests.

\section{Publisher's Note}

Springer Nature remains neutral with regard to jurisdictional claims in published maps and institutional affiliations.

\section{Author details}

${ }^{1}$ Department of Chest Surgery, Takeda General Hospital, 3-27 Yamaga, Aizuwakamatsu 965-8585, Japan. ${ }^{2}$ Department of Chest Surgery, Fukushima Medical University, 1 Hikarigaoka Fukushima, Fukushima 960-1295, Japan. 
Received: 14 November 2017 Accepted: 26 February 2018

Published online: 06 March 2018

\section{References}

1. Guillan R AT, Garcin R. Le syndrom paralytique unilateral global des nerfs craniens. Bull Med Hop (Paris). 1926;50:456-460.

2. Hakusui S, Fujishiro K, Takahashi A. An autopsied case of primary epipharyngeal rhabdomyosarcoma presenting Garcin syndrome. Jpn J Med. 1991:30:379-82

3. Kawaida M, Kanzaki J, Inuyama Y. A case of Garcin's syndrome due to metastasis of breast cancer to the temporal bone manifested by the initial symptom of facial palsy. Facial N Res Jpn. 1986;6:113-6.

4. Kakimoto S, Furukawa M, Kondo A. Prostatic cancer with Garcin syndrome: a case report. Nishinihon J Urol. 1991;53:1051-1055.3.

5. Imanishi J, Adachi H, Kaibara H, Mizukami Y, Kitagawa M. A case of multiple cranial nerve palsies due to metastasis of pulmonary adenocarcinoma to the base of skull. Iryo. 1975;29:637-42.

6. Fujii M, Kiura K, Takigawa N, Yumoto T, Sehara Y, Tabata M, Tanimoto M. Presentation of Garcin syndrome due to lung cancer. J Thorac Oncol. 2007; 2:877-8.

7. Toh T, Yamabe M, Hagiwara S, Watanabe K, Tsurusako S, Ueda M. A case of lung adenocarcinoma with the incipient symptoms of paralysis of the hypoglossal nerve. J Oral Maxillofac Surg. 2007;53:439-43.

8. $\quad$ Aida $Y$, Igarashi $A$, Inoue $S$, Abe $S$, Shibata $Y$, Kubota I. A case of lung adenocarcinoma exhibiting Garcin syndrome. J. Jpn. Respir. Soc. 2010; 48:66-9.

9. Nagashima O, Nanba Y, Kuriyama S, Takekawa H, Kadoya K, Katsura Y, Nanjo Y, Toru K, Yoshimura Y, Sasaki S, Tominaga S. A case of highly doubtful lung cancer detected by one side characteristic-cranial neuropathy (Garcin syndrome). Jpn J Chest Dis. 2011;70:192-7.

10. Moriyama Y, Watanabe K, Shinkai M, Goto H, Ishigatubo Y, Kaneko T. A case of small cell lung cancer with Garcin syndrome. Jpn. J. Lung Cancer. 2013; 53:755-9.

11. Mutsukura K, Tsuboi Y, Imamura A. Garcin syndrome in a patient with rhinocerebral mucormycosis. Brain Nerve. 2004;56:231-5.

12. Sugiura I. Surgical management of metastatic bone involvement by lung cancer. Jpn J Chest Dis. 1985:44:521-8.

13. Eguchi K, Saijo N, Shinkai T. Recent status of the diagnosis and treatment of bone metastasis in patients with advanced lung cancer. Jpn. J. Cancer Chemother. 1987;14:1696-703.

14. Mochizuki T, Ishii G, Nagai K. Pleomorphic carcinoma of the lung: clinicopathologic characteristics of 70 cases. Am J Surg Pathol. 2008;32: 1727-35.

\section{Submit your next manuscript to BioMed Central and we will help you at every step:}

- We accept pre-submission inquiries

- Our selector tool helps you to find the most relevant journal

- We provide round the clock customer support

- Convenient online submission

- Thorough peer review

- Inclusion in PubMed and all major indexing services

- Maximum visibility for your research

Submit your manuscript at www.biomedcentral.com/submit 